\title{
La reforma católica en España y la polémica anti-musulmana: los decretos tridentinos en el Catecismo del Sacromonte.
}

The catholic reformation in Spain and the anti-muslim polemic: the Tridentine Decrees in the Catecismo del Sacromonte

\author{
( Clara Lucía Roig \\ Universidad de Buenos Aires, Argentina
}

Fecha de Recepción: Noviembre 2018. Fecha de Aceptación: Diciembre 2018.

\begin{abstract}
Resumen
El objetivo de este trabajo es analizar la influencia de las resoluciones del Concilio de Trento en el Catecismo del Sacromonte, un catecismo para moriscos datado en 1588 cuyo autor es un anónimo jesuita. Utilizaremos el método comparativo, confrontando dicho documento con una fuente de principios del siglo XVI: la Confusión o confutación de la Secta Mahomética y del Alcorán de Juan Andrés. Comenzamos ubicando nuestro Catecismo en relación con el particular momento histórico en el que fue redactado, con un Papado que intenta imponer el reconocimiento de los resultados del Concilio en todo el mundo, más allá del grado de la amenaza protestante en cada región. Para comprender el alcance de esta influencia comparamos la fuente con otra, pretridentina y anterior a la Reforma protestante, que consiste en un tratado anti-musulmán encargado por los Reyes Católicos, escrito por un musulmán converso y publicado en 1515.
\end{abstract}

\begin{abstract}
The objective of this work is to analyze the influence of the resolutions of the Council of Trent in the Catecismo del Sacromonte, a catechism for Moriscos dated from 1588 which author is an anonymous Jesuit. We use the comparative method, confronting the document with a source from the beginning of the XVIth century: the Confusion o confutación de la Secta Mahomética y del Alcorán of Juan Andrés. We begin by thinking about the relationship between the Catecismo and the particular moment in which it was written, with a Papacy that tries to impose the acknowledgment of the results of the Council of Trent in the entire world, beyond the degree of the protestant menace in each region. With the intention of understanding the reach of this influence we compare the source with another one, pretridentine and previous to the protestant Reformation, that is an anti-muslim treaty ordered by the Catholic Kings, written by a convert muslim and published in 1515 .
\end{abstract}

* Artículo entregado en el marco de las VII Jornadas de Reflexión Histórica: Las formas del conflicto religioso y de la violencia simbólica en el espacio cultural europeo (siglos XIV a XVIII): actores, dispositivos, escenarios, estrategias", organizadas por el Instituto de Historia Antigua y Medieval, (Facultad de Filosofía y Letras, Universidad de Buenos Aires), el 5 de diciembre de 2018

\section{Palabras clave}

Catecismo Concilio de Trento Moriscos Compañía de Jesús

Keywords Catechism Council of Trent Moriscos Society ofjesus 
En este trabajo analizaremos un catecismo para moriscos de fines del siglo XVI: el llamado Catecismo del Sacromonte. Este catecismo fue encontrado recientemente en el monasterio del Sacromonte de Granada y publicado en el año 2002 en una edición hecha por Luis Resines. Es un catecismo anónimo pero, por ciertos datos del mismo texto, se sabe que fue escrito por un jesuita en 1588 (Resines, 2002: 44). Mi intención es contextualizar la fuente en el marco de la Europa postridentina, considerando la posición que entonces tenía la Compañía de Jesús dentro de la Iglesia. La hipótesis que nos guía es que, pese a que este catecismo está pensado para la evangelización de moriscos y no para refutar ideas y prácticas protestantes ante una población que estuviera expuesta a su influencia, se puede encontrar relaciones en aspectos centrales del texto con los decretos del cónclave contrarreformista por antonomasia: el Concilio de Trento.

Para comprobar esto tendremos en cuenta, por un lado, estos decretos mismos y, también, dos catecismos muy cercanos al Concilio tridentino: el Catecismo Romano y el catecismo de Pedro Canisio SJ. Por otro lado, para visualizar la magnitud del cambio de enfoque respecto al problema de la evangelización, compararemos nuestra fuente principal con la Confusión o confutación de la Secta Mahomética y del Alcorán de Juan Andrés, que es un tratado anticoránico publicado en 1515 y de gran difusión durante todo el siglo XVI. Más allá de ciertos debates sobre su autoría (Szpiech, 2012: 318), según la misma fuente el autor es un moro convertido al cristianismo y a quien, luego de haberse dedicado a traducir el Corán, le fue encomendado por los Reyes Católicos escribir un tratado para la propagación de la fe católica entre los recientemente conquistados.

Para la contextualización de nuestra fuente principal debemos resaltar, en primer lugar, la importancia que adquirieron los catecismos o "doctrinas cristianas" en el siglo XVI (Sánchez Herrero, 1990: 253). En este siglo aumentaron notablemente en cantidad, ya que quienes propugnaban una reforma de la Iglesia católica (incluso antes de Lutero) insistían en la importancia de la educación, resaltando la ignorancia del clero y la población respecto a los lineamientos de la fe católica. Luego, durante el proceso llamado de confesionalización, los catecismos fueron un medio privilegiado para expresar y comunicar los aspectos fundamentales de la fe (Ruiz-Rodríguez y Sosa Mayor, 2007: 287).

Como respuesta a este proceso de elaboración de catecismos tanto por parte de católicos como otros que no respondían a los lineamientos de la fe, el Concilio de Trento consideró fundamental la redacción de un catecismo oficial, encomendando a una comisión continuar trabajando bajo la autoridad del Papa en la elaboración de lo que luego fue el Catecismo Romano o Catecismo para los párrocos (Concilio de Trento, 1847 [1564]: 391). Así se confirmaba la necesidad de brindar educación religiosa al clero y por intermedio de éste a la población con una herramienta autorizada directamente por el Papa: el Catecismo Romano es necesario porque "han salido al mundo, para pervertir las almas con doctrinas varias y peregrinas, aquéllos Profetas falsos" que "además de muchos abultados libros con que procuraron trastornar la fe Católica (de los cuales fue fácil precaverse, por contener heregías manifiestas) escribieron también innumerables librillos al parecer piadosos, con los cuales es increíble cuán fácilmente engañaron las ánimas incautas de los simples" (Pio V, 1785 [1566]: 2).

El Catecismo Romano, pensado como una guía para el clero, dejaba en su prólogo a criterio de este último la forma de transmitir la doctrina cristiana a los fieles: "acerca del orden de enseñar observará aquél que pareciere más acomodado así al auditorio, como al tiempo" (Pio V, 1785 [1566]: 6). Esto dio pie a que se continuaran escribiendo catecismos para situaciones particulares como es el caso de nuestro catecismo para moriscos. 
Además del Catecismo Romano hubo otro catecismo de importancia similar: entre 1555 y 1558 Pedro Canisio, teólogo de la Compañía de Jesús, redactó tres catecismos, dirigidos a tres tipos de público diferentes, por encargo del emperador Fernando I a San Ignacio. El emperador veía al catecismo como una herramienta imprescindible para frenar el avance del protestantismo en el Imperio. El catecismo más extenso de Canisio, dirigido a los párrocos al igual que luego el Romano, fue declarado de "lectura obligatoria" tanto en el Sacro Imperio como en España (Zafra Molina, 2015: 318). La importancia de este catecismo jesuita es difícil de exagerar: estuvo cerca de ser declarado oficial, lo que no prosperó por las disputas entre la Compañía de Jesús y la orden dominica, y también por las luchas entre el Papado, el Sacro Imperio y España. Sin embargo fue en gran medida tenido en cuenta por la comisión que redactó el Catecismo Romano (Zafra Molina, 2015: 328).

La importancia del catecismo de Canisio nos da la pauta de la centralidad de la educación y la evangelización para la Compañía de Jesús, que por más que era una orden nueva fue la elegida por el Emperador para redactar esta obra clave en su lucha contra el avance del protestantismo. En este sentido la Compañía, dado su objetivo de defensa y propagación de la fe, se plegó rápidamente a los lineamientos de la reforma católica.

Además del aumento en general de los catecismos que mencionábamos más arriba, los catecismos especiales para moriscos fueron un fenómeno del siglo XVI: previo a la conquista de Granada en 1492 las conversiones de moros no eran un problema masivo (Sánchez Herrero, 1990: 248), y con posterioridad al 1600 el problema morisco ya no era visto como solucionable mediante la evangelización, lo que desembocó en las grandes expulsiones de 1609-1614. Es por esto que cuando deseamos comparar las estrategias discursivas de la evangelización de fines del siglo XVI con las previas al Concilio de Trento y a la Reforma protestante nos debemos remitir a otro género de escritura, los anticoranes, que fueron libros de polémica contra la religión musulmana cuyo origen se puede situar en el siglo VIII (Ruiz García, 2003: 14). Esta tradición fue influida por los franciscanos y dominicos que se dedicaron a predicar contra el Islam en el norte de África, y pretendía basarse en la "vía del razonamiento" para atacar a la fe contraria y lograr las conversiones (Ruiz García, 2003: 23). El anticorán que elegimos se sitúa en el período que comienza luego de la conquista de Granada con las campañas de cristianización del infiel y fue encargado por los Reyes Católicos.

Ambos géneros de escritura, los anticoranes y los catecismos para moriscos, tienen como objetivo que el destinatario abandone las creencias musulmanas y abrace la fe católica. Sin embargo, las estrategias utilizadas son diferentes: en el primer caso lo fundamental es el ataque del Islam mediante lo que se muestra como la "razón natural", y la intención del tratado es demostrar la verdad del catolicismo a través de las mismas palabras del Corán, mostrando que incluso en una escritura adulterada y con mentiras e inventos estaba presente la verdad de Cristo (Juan Andrés, 2003 [1515]: 210). En el segundo caso al ataque total y completo del Islam, negando cualquier verdad de éste (Resines, 2002: 210), se agrega la enunciación de los principios fundamentales de la fe católica, como en todo catecismo.

Los argumentos contra el Islam tanto del Catecismo como de la Confutación son similares: combinan argumentos contra la persona de Mahoma (insultos, la profesión de mercader, la caracterización de él como una persona ambiciosa, lujuriosa e ignorante), ${ }^{1}$ contra los seguidores, a los que caracterizan como ignorantes y brutos también y marcan su anterior religión pagana, ${ }^{2}$ y contra las doctrinas, a las que caracterizan como una perversión de las doctrinas de Cristo mezcladas con aspectos del judaísmo y con mandamientos escritos por Mahoma para satisfacer sus ambiciones y atribuidos a Dios (Resines, 2002: 144; Juan Andrés, 2003 [1515]: 150-151). Sin embargo la
1. "Y según era Mahoma y sus dichos, actos y fechos, el qual fue todo lleno de superbia, vanidad y vanagloria, lleno de luxuria, vengador y cruel, vazío de toda virtud y caridad, muy apartado de misericordia y piedad" Juan Andrés (2003 [1515]: 227).

2. "Mahoma començó y acabó de fazer esta ley o secta de los moros entre gente muy ruda, necia y gente grossera y rústica, gente ydólatra, vazíos de todo saber, ca entre essa gente no se fallava ningún lógico ni astrólogo ni philósopho ni físico, sino todos temporales, todos dados al comer y al bever y a luxuriar" Juan Andrés (2003 [1515]: 218). 
estrategia de defensa del cristianismo de ambas fuentes es diferente, y no puede ser atribuida únicamente a las diferencias entre ambos géneros sino que hay marcas que podemos atribuir tanto a la época y que podemos atribuir a la especificidad jesuita del Catecismo.

Si bien en ningún momento el autor del Catecismo menciona directamente el protestantismo, hace constantes alusiones que nos hacen ver a este autor como postridentino. Considero que los aspectos más notables son cuatro: la importancia de la Iglesia como institución y sus jerarquías, la importancia de los sacramentos para la obtención de la gracia, la necesidad de distinguir los malos cristianos de la fe cristiana, y las aclaraciones respecto al correcto uso de las imágenes, aspecto que si bien es importante en la polémica contra el Islam en sí, también tiene relación con el problema del protestantismo.

El tema de la Iglesia católica como única autoridad abarca tres capítulos enteros del Catecismo y vuelve a retomarse en otras ocasiones, como cuando se afirma que la única condición necesaria para no ser infiel es pensar "creo todo lo que cree la santa Iglesia Romana y créolo como verdad infalible de Dios" (Resines, 2002: 208).

En este caso es probable que el jesuita tuviera en mente el problema del protestantismo, ya que cree necesario explicar "por qué Dios no da a cada uno inmediatamente" la fe infusa sino que la transmite a través de la jerarquía eclesiástica, puntualizando que "la cabeza sea una porque si oviesse muchas iguales fácilmente habría cismas y bandos que destruyan la república cristiana", y que "todo está en la santa Iglesia Romana que tiene los perfectos y verdaderos sacramentos" (Resines, 2002: 194).

La Confusión... menciona el tema de la herejía, pero desde una óptica muy diferente, ya que muestra a la Iglesia Católica como cohesionada y triunfante sobre las herejías: "no solamente convertieron los discípulos de Jesucristo predicando y faziendo miraglos, más aún disputando y declarando la verdad y confundiendo heréticos y malos que argüían contra la verdad. Y así fue disputada y por la verdad exalçada la fe cristiana fasta que quedó para siempre lúzida" (Juan Andrés, 2003 [1515]: 221).

El tema de la necesidad de los sacramentos para la obtención de la gracia, si bien es un punto que está presente en todo catecismo, cobra mayor importancia e independencia dentro de la estructura de este género a partir de la reforma católica como reacción al protestantismo (Rodríguez, 1985a: 477). Se nota esta postura del autor cuando al preguntar en el texto el novicio qué ha de hacer el hombre para obtener la gracia, el sacerdote contesta: "penitencia de sus culpas y enmendarse, recebir los sacramentos, orar, y guardar la ley divina y eclesiástica, ejercitarse con obras de misericordia con el prójimo, finalmente obrar bienes y sufrir males" (Resines, 2002: 215). En este fragmento es notoria la contraposición con la doctrina de la sola fide de Lutero.

Respecto a los sacramentos también es notoria la mención por su nombre de la doctrina de la transubstanciación, cuando el jesuita explica al novicio el sacramento de la eucaristía.

Por el contrario, en el tratado de Juan Andrés, concebido antes de la Reforma, no se mencionan siquiera los sacramentos. Sí se puede deducir la importancia que se le da a las buenas obras dentro de la teología cristiana ya que buena parte de los argumentos contra Mahoma y el Islam giran en torno a ciertas permisiones de la fe musulmana, que son catalogadas como pecados capitales (gula, lujuria y avaricia permitidas en el Paraíso). Sin embargo el autor no considera necesario hacer un apartado especial sobre el tema, como sí sobre la naturaleza divina de Cristo y sobre la virginidad de María, ya que sobre esto gira su argumentación. 
Otro aspecto que considero importante es el de la mención de los malos cristianos, de su condena -que sólo corre por cuenta de Dios y no de los hombres-y de la necesidad de aclarar que la existencia de los malos cristianos no impugna la validez de la Iglesia Romana. Este problema, si bien puede ser ligado con críticas corrientes hechas por los conversos de otras religiones, guarda también mucha relación con las críticas de Lutero a la Iglesia católica, particularmente al problema de la corrupción de la curia.

En el Catecismo, el crecimiento del Islam es visto como un castigo de Dios por el pecado de los malos cristianos (Resines, 2002: 250). Este argumento, si bien no era nuevo en el siglo XVI, no se menciona en la Confusión, en la que en cambio las razones que se dan del crecimiento del Islam son la ignorancia de los seguidores de Mahoma, su anterior religión pagana que los hacía de una bajeza mayor a los de Cristo y los apóstoles, la habilidad argumentativa de Mahoma al escribir como leyes de Dios todo lo que deseaban sus seguidores, y también el uso de la fuerza, que es contrapuesto por el autor a la predicación pacífica de los Evangelios (Juan Andrés, 2003 [1515]: 225). Podemos ver que el tema de la importancia de las obras fue en aumento durante el siglo XVI y en el Catecismo se les da un lugar mucho mayor.

Por último, el tema de las imágenes es abordado como una crítica a la postura de la prohibición del Islam, pero la explicación es similar a la respuesta dada al protestantismo en el Concilio de Trento: el Catecismo afirma que las imágenes son "no para creer que en ellas hay divinidad alguna (...) sino para honra de Dios y de sus sanctos" (Resines, 2002: 267) mientras que el Concilio decreta que "se les debe dar el correspondiente honor y veneración: no porque se crea que hay en ellas divinidad (...) sino porque el honor que se da a las imágenes se refiere a los originales representados en ellas" (Concilio de Trento, 1847 [1564]: 330).

Pese a que esta es una importante diferencia entre ambas religiones, Juan Andrés no menciona siquiera el tema de las imágenes en su tratado. Esto es una muestra más de que este tema no estaba presente necesariamente en la polémica anti alcoránica, y que su aparición en el Catecismo está también vinculada con la polémica con el protestantismo.

Estos cuatro aspectos fundamentales que encontramos presentes a lo largo de todo el Catecismo del Sacromonte nos muestran la influencia del Concilio de Trento en su autor. Podemos ver entonces que en 1588 la Compañía de Jesús había incorporado el espíritu tridentino a sus estrategias de evangelización y a la defensa de la ortodoxia católica, inclusive en contextos en los que el adversario no era el protestantismo. Esto supuso un cambio en el discurso evangelizador, ya que en las estrategias anteriores a la Reforma los argumentos no se apartaban de la polémica entre el cristianismo y el Islam. Se podría sugerir que, como orden nueva y en sus disputas con otras órdenes, esto puede haber sido una estrategia para hacer gala de su propia ortodoxia. 


\section{Q Bibliografía:}

" Canisio, P. (1798 [1555]). Catecismo católico trilingüe. Imprenta de Don Benito Cano. Madrid.

»Concilio de Trento (1847 [1564]). El Sacrosanto y Ecuménico Concilio de Trento. Imprenta de D. Ramón Martín Indar. Barcelona.

» Juan Andrés (2003 [1515]). Confusión o confutación de la secta mahomética y del Alcorán [1515]. Editorial Regional de Extremadura. Mérida 2003

»Pio V, Catecismo del Santo Concilio de Trento para los párrocos [1566]. Imprenta Real. Madrid 1785

» Prosperi, A. (2008). El concilio de Trento. Una introducción histórica. Ávila: Junta de Castilla y León.

"Resines, L. (ed.) (2002). Catecismo del Sacromonte y Doctrina Christiana del Fr. Pedro de Feria. Conversión y evangelización de moriscos e indios. Madrid: Consejo superior de investigaciones científicas.

"Rodríguez, P. (1985a). "La cuestión histórico-doctrinal del Catecismo Romano", Scripta theologica: revista de la Facultad de Teología de la Universidad de Navarra, Pamplona, Vol. 17, Fasc. 2, pp. 467-485.

"Rodríguez, P. (1985b). “El manuscrito original del Catecismo Romano”, Scripta theologica: revista de la Facultad de Teología de la Universidad de Navarra, Pamplona, Vol. 17, Fasc. 2, pp. 487-552.

»Rodríguez, P. (1990). “La edición crítica del Catecismo Romano”, Scripta theologica: revista de la Facultad de Teología de la Universidad de Navarra, Pamplona, Vol. 22, Fasc. 2, pp. 539-594.

»Ruiz García, E. (2003). “Estudio preliminar”, en Juan Andrés, Confusión o confutación de la secta mahomética y del Alcorán. Mérida: Editorial Regional de Extremadura.

» Ruiz-Rodríguez, J. I. y Sosa Mayor, Í. (2007). "El concepto de la 'confesionalización' en el marco de la historiografía germana”, Studia Historica Historia Moderna, Madrid: Marcial Pons, Madrid, Vol. 29, pp. 279-305.

"Sánchez Herrero, J. (1990). “Alfabetización y Catequesis en España y en América durante el siglo XVI”, Saranyana, J.-I. et al. (eds.), Evangelización y teología en América (siglo XVI): X Simposio Internacional de Teología de la Universidad de Navarra. Servicio de Publicaciones de la Universidad de Navarra, Vol. 1, pp. 237-263.

»Szpiech, R. (2012). "Preaching Paul to the Moriscos: the Confusión o confutación de la secta mahomética y del Alcorán (1515) of Juan Andrés", La Corónica, Vol. 41.1, pp. 317-343.

»Zafra Molina, R. (2015). "La Suma de Canisio: catecismo del Concilio de Trento", Anuario de historia de la Iglesia, Vol. 24, pp. 311-330. 